\title{
Changes in cerebral and somatic oxygenation during stage 1 palliation of hypoplastic left heart syndrome using continuous regional cerebral perfusion
}

\author{
George M. Hoffman, MD \\ Eckehard A. Stuth, MD \\ Robert D. Jaquiss, $M^{\mathrm{C}}$ \\ Patrick L. Vanderwal, MSP \\ Susan R. Staudt, MDa \\ Todd J. Troshynski, MD ${ }^{\mathrm{a}}$ \\ Nancy S. Ghanayem, MD ${ }^{\mathrm{b}}$ \\ James S. Tweddell, MD ${ }^{\mathrm{c}}$
}

From the Departments of Pediatric Anes-
thesiology, ${ }^{\text {a }}$ Critical Care Medicine, ${ }^{\mathrm{b}}$ and
Cardiovascular Surgery, ${ }^{\mathrm{c}}$ Children's Hospi-
tal of Wisconsin and Medical College of
Wisconsin, Milwaukee, Wis.

Read at the Eighty-third Annual Meeting of The American Association for Thoracic Surgery, Boston, Mass, May 4-7, 2003.

Received for publication May 1, 2003; revisions requested Aug 11, 2003; accepted for publication Aug 13, 2003.

Address for reprints: George M. Hoffman, MD, Anesthesiology 735, Children's Hospital of Wisconsin, 9000 West Wisconsin Avenue, Milwaukee, WI 53226 (E-mail: ghoffman@mcw.edu).

J Thorac Cardiovasc Surg 2004;127:223-33 $0022-5223 / \$ 30.00$

Copyright ( $\odot 2004$ by The American Association for Thoracic Surgery

doi:10.1016/j.jtcvs.2003.08.021
Objectives: Stage 1 palliation of hypoplastic left heart syndrome requires the interruption of whole-body perfusion. Delayed reflow in the cerebral circulation secondary to prolonged elevation in vascular resistance occurs in neonates after deep hypothermic circulatory arrest. We examined relative changes in cerebral and somatic oxygenation with near-infrared spectroscopy while using a modified perfusion strategy that allowed continuous cerebral perfusion.

Methods: Nine neonates undergoing stage 1 palliation for hypoplastic left heart syndrome had regional tissue oxygenation continuously measured by frontal cerebral and thoraco-lumbar (T10-L2) somatic (renal) reflectance oximetry probes $\left(\mathrm{rSO}_{2}\right.$, INVOS; Somanetics, Troy, Mich). Surgery was accomplished using cardiopulmonary bypass with whole-body cooling $\left(18^{\circ} \mathrm{C}-20^{\circ} \mathrm{C}\right)$ and regional cerebral perfusion through the innominate artery at flow rates guided by estimated minimum flow requirements and measured $\mathrm{rSO}_{2}$ during reconstruction of the aortic arch. Data were logged at 1-minute intervals and analyzed using repeated measures analysis of variance.

Results: A total of 3176 minutes of data were analyzed. Prebypass cerebral $\mathrm{rSO}_{2}$ was $65.4 \pm 8.9$, and somatic $\mathrm{rSO}_{2}$ was $58.9 \pm 12.4(P<.001$, cerebral vs somatic). During regional cerebral perfusion, cerebral $\mathrm{rSO}_{2}$ was $80.7 \pm 8.6$, and somatic $\mathrm{rSO}_{2}$ was $41.4 \pm 7.1(P<.001)$. Postbypass cerebral $\mathrm{rSO}_{2}$ was $53.2 \pm 14.9$, and somatic $\mathrm{rSO}_{2}$ was $76.4 \pm 7.7(P<.001)$. The risk of cerebral desaturation was significantly increased after cardiopulmonary bypass.

Conclusions: Cerebral oxygenation was maintained during regional cerebral perfusion at prebypass levels with deep hypothermia. However, after rewarming and separation from cardiopulmonary bypass, cerebral oxygenation was lower compared with prebypass or somatic values. These results indicate that cerebrovascular resistance is increased after deep hypothermic cardiopulmonary bypass, even with continuous perfusion techniques, placing the cerebral circulation at risk postoperatively.

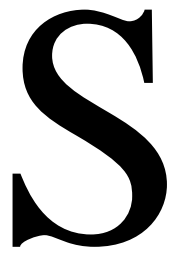

trategies to improve outcome after cardiopulmonary bypass (CPB) and circulatory arrest for complex congenital heart disease have been directed at optimizing metabolic suppression and oxygen delivery with adequate cooling time and $\mathrm{pH}$-stat perfusion strategies, ${ }^{1,2}$ reducing hemodilution ${ }^{3,4}$ and ischemia time, ${ }^{5}$ and preventing endothelial dysfunction and related injury. ${ }^{1,6-9}$ Near-infrared spectroscopy (NIRS) has aided the study of regional perfusion by providing a noninvasive 
estimate of tissue oxyhemoglobin saturation. ${ }^{10-12}$ Continuous regional cerebral perfusion (RCP) can provide blood flow to the head during aortic arch reconstruction, ${ }^{13}$ and maintenance of cerebral oxygen saturation during RCP has been demonstrated with NIRS. ${ }^{12,14}$ However, delayed abnormalities in regional circulation may occur after deep hypothermic CPB and deep hypothermic circulatory arrest (DHCA) because of prolonged changes in cerebrovascular function. ${ }^{15,16}$ We hypothesized that such alterations in regional autoregulation, in combination with inadequate global oxygen delivery post-CPB secondary to functional and anatomic circulatory limitations, ${ }^{17}$ place tissues in selective vascular beds at risk for ischemia. ${ }^{17-19}$ We used a commercially available NIRS device to assess changes in oxyhemoglobin saturation in two different regional circulations (cerebral ${ }^{10,11,14}$ and thoraco-lumbar or somatic ${ }^{13,20}$ ) before, during, and immediately after stage 1 palliation (S1P) of hypoplastic left heart syndrome, hypothesizing that continuous cerebral perfusion would preserve cerebral oxygenation both during and after CPB.

\section{Methods}

\section{Patients and Clinical Techniques}

Nine patients undergoing stage 1 palliation for hypoplastic left heart syndrome were studied. Institutional review board approval, parental consent for administration of phenoxybenzamine, and clinical physiologic data were obtained for all patients. Hypercapnia was used to control pulmonary blood flow and improve systemic oxygen delivery as necessary before $\mathrm{CPB} .{ }^{21}$ High-dose, synthetic, opioid-based anesthesia with supplemental isoflurane was induced in all patients, with opioid infusions maintained into the postoperative period. ${ }^{22}$ Surgical repair was performed using techniques previously described: relief of arch obstruction, ascending aorta-to-pulmonary artery trunk anastomosis, homograft augmentation of the aortic arch, placement of a systemic-to-pulmonary shunt, and creation of unrestrictive interatrial patency. ${ }^{23} \mathrm{CPB}$ was initiated through a synthetic shunt anastomosed to the innominate artery using a Stockert SC roller pump (Sorin Biomedical, Irvine, Calif) and a Dideco Lilliput 1 hollow fiber membrane oxygenator (Cobe Cardiovascular, Arvada, Calif). CPB management consisted of target flows of 2 to $4 \mathrm{~L} \cdot \mathrm{m}^{2} \cdot \min$ and hematocrit $25 \%$ to $30 \%$ with pH-stat blood gas management for uniform cooling $\left(18^{\circ} \mathrm{C}-20^{\circ} \mathrm{C}\right)$ at nasopharyngeal and bladder sites (minimum time 30 minutes); continuous cerebral perfusion through the innominate shunt at pump flows of 30 to $70 \mathrm{~mL} \cdot \mathrm{kg} \cdot \min ^{13}$ during neoaortic and arch reconstruction; and resumption of full support at target flows of 3 to $4 \mathrm{~L} \cdot \mathrm{m}^{2} \cdot \min$ after somatic and cardiac reperfusion, with a gradual switch to alpha-stat strategy and hemoconcentration during rewarming to a target hematocrit of $35 \%$ or greater before separation from CPB. All patients received aprotinin $1.7 \times 10^{6} \mathrm{KIU} / \mathrm{m}^{2}$ and methylprednisolone $10 \mathrm{mg} / \mathrm{kg}$ before $\mathrm{CPB}$, and phenoxybenzamine $0.25 \mathrm{mg} / \mathrm{kg}$ was added to the pump prime. Separation from CPB occurred after initiation of infusions of milrinone $\left(0.5 \mu \mathrm{g} \cdot \mathrm{kg}^{-1} \cdot \mathrm{min}^{-1}\right)$, dopamine $(3 \mu \mathrm{g}$. $\left.\mathrm{kg}^{-1} \cdot \mathrm{min}^{-1}\right)$, and epinephrine or norepinephrine $(0.05-0.15 \mu \mathrm{g}$. $\mathrm{kg}^{-1} \cdot \min ^{-1}$ ) or both as needed to achieve an approximate systemic vascular resistance index of 10 to 12 Wood units and adequate contractility. Modified ultrafiltration was used in all patients immediately after separation from CPB. Post-CPB hemodynamic management included a primary target of $\mathrm{SvO}_{2}$ of $50 \%$ or greater, including mean arterial pressure greater than $45 \mathrm{~mm} \mathrm{Hg}$, $\mathrm{SaO}_{2}$ greater than $75 \%$, and hematocrit greater than $40 \%$ as previously described. ${ }^{17}$ No alterations from standard treatment were undertaken during the study period except to use $\mathrm{rSO}_{2}$ data to guide RCP to a target of $75 \%$ or greater.

\section{Monitoring and Data Acquisition}

In all patients, blood pressure was invasively monitored with an existing umbilical artery catheter, and atrial pressure was monitored with an umbilical vein catheter if present or an atrial line placed at the time of surgery. Arterial oxygen saturation was monitored continuously in the lower extremity (Nellcor N200; Pleasanton, Calif). Systemic venous oxygenation $\left(\mathrm{SvO}_{2}\right)$ was monitored continuously during $\mathrm{CPB}$ from the venous drainage (Terumo CDI-500; Ann Arbor, Mich) and post-CPB using a 4FR optical catheter (Abbott Oxycath; Abbott Laboratories, Abbott Park, Ill) placed in the superior vena cava before separation from CPB. Airway gas tensions were monitored using Raman spectroscopy (Ohmeda Rascal-2, Louisville, Colo). Data from these sources were captured on a clinical information system (GE/ Marquette Solar; Milwaukee, Wis) and trended at 5-minute intervals. NIRS probes were placed on the patient's midline forehead (cerebral) and slightly to the right of midline on the T10-L2 posterior flank (somatic) after entry into the operating room. The probes were monitored by a dual-detector device (Somanetics INVOS 5100A, Troy, Mich) and trended at 1-minute intervals. $\mathrm{CPB}$ flows, temperatures, and pressures were captured at 5-minute intervals. Arterial and venous blood gases were obtained at clinically appropriate intervals, with tensions reported at $37^{\circ} \mathrm{C}$ (Radiometer ABL, Copenhagen, Denmark).

\section{Statistical Analysis}

Prospective, electronically captured, and manually recorded data were inserted into a common statistical database. In addition to measured variables, derived variables were calculated as follows: organ perfusion pressure $(\mathrm{PP})=$ mean arterial blood pressure central venous pressure; cerebral Da- $\mathrm{rO}_{2}=\mathrm{SaO}_{2}-$ cerebral $\mathrm{rSO}_{2}$; somatic Da- $\mathrm{rO}_{2}=\mathrm{SaO}_{2}-$ somatic $\mathrm{rSO}_{2} ; \mathrm{DrSO}_{2}$ (cerebral-somatic) $=$ cerebral $\mathrm{rSO}_{2}-$ somatic $\mathrm{rSO}_{2}$; oxygen content PP index $\left(\mathrm{CaO}_{2} \cdot\right.$ PPI $)=1.34 \cdot$ hemoglobin $\cdot$ PP. Each patient's clinical data were divided into 5 major time periods consisting of 11 intervals, demarcated by preinduction baseline, anesthesia induction, surgical incision, initiation of $\mathrm{CPB}$, initiation of myocardial ischemia with aortic crossclamp, initiation of RCP, resumption of $\mathrm{CPB}$, removal of aortic crossclamp, separation from CPB, completion of modified ultrafiltration, and surgical closure. Within each interval for each patient, data were collapsed into 5 epochs of equal duration to create 55 distinct epochs for subsequent statistical analysis. Data were summarized within intervals and periods, and presented as mean $\pm \mathrm{SD}$ if continuous and number and percent if discrete, with $95 \%$ confidence intervals (CIs) calculated as appropriate. Generalized least squares regression and analysis of variance (ANOVA) techniques were used to account for repeated measurements within patients and time intervals. Data were com- 


\section{TABLE 1. Demographic data}

\begin{tabular}{lc}
\hline Characteristic & \\
\hline Age (d) & $4.9 \pm 1.7$ \\
Weight $(\mathrm{kg})$ & $2.84 \pm 0.59$ \\
$\mathrm{BSA}\left(\mathrm{m}^{2}\right)$ & $0.179 \pm 0.038$ \\
Preoperative $\mathrm{Hgb}(\mathrm{g} / \mathrm{dL})$ & $40 \pm 5$ \\
Preoperative $\mathrm{SpO}_{2}(\%)$ & $89 \pm 3$ \\
Preoperative mechanical ventilation & $6 / 9(67 \%)$ \\
Preoperative inotropes & $5 / 9(55 \%)$ \\
CPB duration (min) & $113 \pm 12$ \\
RCP duration (min) & $58 \pm 10$
\end{tabular}

Data are presented as mean \pm SD or number (\%).

$B S A$, Body surface area; $H g b$, hemoglobin; $C P B$, cardiopulmonary bypass; $R C P$, regional cerebral perfusion.

pared across time periods or intervals by 2 -sided $t$ tests on regression coefficients or by 2-way analysis of variance for repeated measures for comparisons of means and by the likelihood-ratio test for risk comparisons, with significance cutoff at $P<.05$ after correction for multiple comparisons by the Bonferroni method. All calculations were performed with a standard statistical package (STATA version 8; Stata Corp, College Station, Tex).

\section{Results}

Demographic and baseline clinical data from the 9 patients are summarized in Table 1. All patients underwent S1P and survived to hospital discharge; 3176 minutes of data were available for analysis (353 min/patient, range 304-418 minutes). Hypothermic RCP was accomplished in all patients at a flow rate of $47 \pm 22 \mathrm{~mL} \cdot \mathrm{kg}^{-1} \cdot \mathrm{min}^{-1}(75 \pm 35 \mathrm{~mL}$ $\left.\mathrm{m}^{-2} \cdot \min ^{-1}\right)$.

Regional saturation data differed markedly during periods of perfusion and surgical repair. Preincision baseline cerebral $\mathrm{rSO}_{2}$ was $68 \% \pm 4 \%$ until $\mathrm{CPB}$, and baseline somatic $\mathrm{rSO}_{2}$ was $68 \% \pm 8 \%$, decreasing to $56 \% \pm 14 \%$ before CPB. During cooling on CPB, cerebral $\mathrm{rSO}_{2}$ increased to $87 \% \pm 8 \%$, and somatic $\mathrm{rSO}_{2}$ increased to $77 \%$ $\pm 13 \%$. During RCP, cerebral $\mathrm{rSO}_{2}$ was maintained at $81 \%$ $\pm 9 \%$, whereas somatic $\mathrm{rSO}_{2}$ decreased to $41 \% \pm 7 \%$, recovering to $77 \% \pm 10 \%$ and $84 \% \pm 13 \%$, respectively, during rewarming on $\mathrm{CPB}$. After separation from $\mathrm{CPB}$, regional saturation in both measured beds decreased; cerebral $\mathrm{rSO}_{2}$ decreased progressively to $48 \% \pm 7 \%$, whereas the somatic $\mathrm{rSO}_{2}$ decreased but remained above baseline at $78 \% \pm 4 \%$. A summary of regional saturations at major time periods is contained in Table 2. Cerebral and somatic $\mathrm{rSO}_{2}$ were different from each other and from baseline values at all time points $(P<.001)$. Detailed regional saturation data are shown in Figure 1.

The post-CPB decrease in cerebral $\mathrm{rSO}_{2}$ was not solely caused by the reduction in $\mathrm{SaO}_{2}$. Figure 2 shows the $\mathrm{SaO}_{2}$, regional $\mathrm{SaO}_{2}-\mathrm{rSO}_{2}$ difference, and cerebral-somatic $\mathrm{rSO}_{2}$ difference by time period. These data show that regional cerebral oxygen extraction, as approximated by the
TABLE 2. Regional saturations at major time periods

\begin{tabular}{lll}
\hline Time period & \multicolumn{1}{c}{ Cerebral $\mathbf{r S O}_{\mathbf{2}}(\%)$} & \multicolumn{1}{c}{ Somatic $\mathbf{r S O}_{\mathbf{2}}(\%)$} \\
\hline Pre-CPB & $65.4 \pm 8.9(63.2-67.6)$ & $58.9 \pm 12.4(57.8-59.9) \dagger$ \\
CPB (cooling) & $87.2 \pm 7.8(85.0-89.5)^{*}$ & $77.2 \pm 12.5(75.6-78.8)^{*} \dagger$ \\
$\mathrm{RCP}$ & $80.7 \pm 8.6(78.6-83.0)^{*}$ & $41.4 \pm 7.1(39.9-42.8)^{*} \dagger$ \\
CPB (warming) & $76.8 \pm 10.2(74.6-79.0)^{*}$ & $83.5 \pm 12.9(82.2-84.8)^{*} \dagger$ \\
Post-CPB & $53.2 \pm 14.9(51.0-55.5)^{*}$ & $76.4 \pm 7.7(75.3-77.6)^{*} \dagger$
\end{tabular}

Regional saturation data summarized within major operative periods. Data are presented as mean $\pm S D$ and $(95 \%$ confidence intervals). All differences are significant at $P<.001$ by repeated measures ANOVA.

*Differences compared with pre-CPB baseline.

tDifferences between sites.

$\mathrm{SaO}_{2}-\mathrm{rSO}_{2}$ difference, was increased in the post-CPB period relative to somatic beds. The decrease in cerebral $\mathrm{rSO}_{2}$ occurred despite increases in hematocrit, $\mathrm{CO}_{2}$ tension, and mean arterial pressure after separation from CPB, all of which would be expected to favor increases in cerebral blood flow and oxygen delivery. Other potential determinants of cerebral oxygenation such as temperature, pump flow rate, isoflurane concentration, and the $\mathrm{CaO}_{2}$ PPI, an index of regional oxygen availability, also were maintained in the period after separation from CPB. Complete hemodynamic data are detailed in Table 3.

The relationship between cerebral $\mathrm{rSO}_{2}$ and potential determinants (mean arterial blood pressure, central venous pressure, $\mathrm{SaO}_{2}, \mathrm{PaCO}_{2}$, temperature, hematocrit, and isoflurane concentration) were evaluated in a multiple linear least squares regression model, comparing all data before and after CPB. The model significantly related the independent variables to cerebral $\mathrm{rSO}_{2}\left(r^{2}=0.79\right)$, and several parameters were significantly different pre- and post-CPB. The complete model parameters are shown in Table 4.

The risk of regional desaturation was assessed during each period as the proportion of time with $\mathrm{rSO}_{2}$ less than $50 \%$. The overall risks of such cerebral and somatic desaturation were $11 \%$ and $23 \%$, respectively. Somatic $\mathrm{rSO}_{2}$ was threatened after incision (risk $42 \%$, CI $36 \%-48 \%, P<.001$ compared with baseline) and improved during CPB. During $\mathrm{RCP}$, the somatic $\mathrm{rSO}_{2}$ was below the threshold $89 \%$ of the time (CI 84\%-92\%, $P<.001$ compared with baseline), but the risk of somatic desaturation was essentially zero after separation from CPB. In contrast, the risk of cerebral desaturation was minimal until separation from $\mathrm{CPB}$, when it was $21 \%$ (CI 16\%-28\%, $P<.001$ compared with baseline), and continued to increase after withdrawal of volatile anesthesia to $74 \%$ (CI $60 \%-85 \%, P<.001$ compared with baseline). These findings are shown in Figure 3.

\section{Discussion}

The major findings of this study were that cerebral $\mathrm{rSO}_{2}$ decreased post-CPB despite continuous RCP, and that assessment of 2-site regional oxygenation using NIRS tech- 


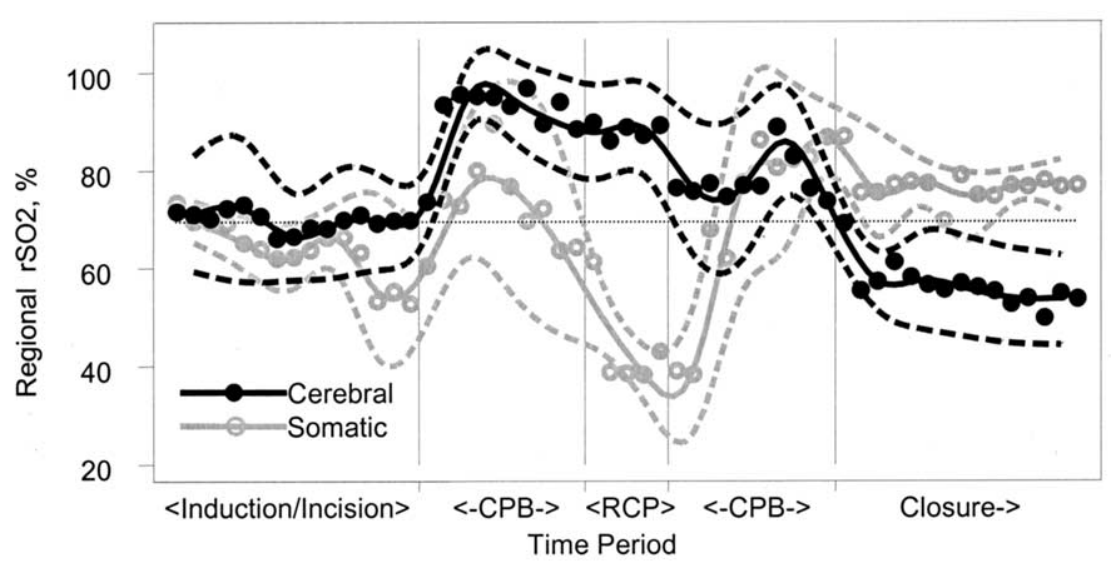

Figure 1. Cerebral and somatic $\mathrm{rSO}_{2}$ during repair. Repair was divided into 5 major periods consisting of 11 intervals as described. Data are shown as mean and SD for each epoch. CPB, Cardiopulmonary bypass; $R C P$, regional cerebral perfusion. Dotted line marks preinduction baseline values.

nology provided information about oxygen delivery distinct from global measures. The dual-path length device that was used measures average hemoglobin saturation in a slice of tissue approximately 1.5 to $2.5 \mathrm{~cm}$ deep, tracks changes in jugular venous saturation closely, and detects changes in tissue oxygenation in a variety of tissues. ${ }^{13,24,25}$ Although no formal calculations of regional blood flow were made in this study, cerebral $\mathrm{rSO}_{2}$ has been shown to closely track changes in jugular venous saturation $\left(r^{2}=0.91\right)$, and thus changes in $\mathrm{rSO}_{2}$ can estimate regional flow-metabolism relationships. ${ }^{26} \mathrm{We}$ attempted to place somatic probes to capture the renal circulation (which normally has a low extraction ratio but is under intense sympathetic control) as a contrast with the cerebral circulation (which normally exhibits intense perfusion-metabolism coupling). This was performed to serve as a within-patient control for factors such as changes in venous volume and to help differentiate changes in global systemic flow from changes in the distribution of regional flows as potential causes of changes in cerebral $\mathrm{rSO}_{2}$.

Interventions to increase cerebral $\mathrm{rSO}_{2}$ may reduce neurologic morbidity in children undergoing $\mathrm{CPB}{ }^{27,28} \mathrm{Al}-$ though absolute thresholds of $\mathrm{rSO}_{2}$ for neurologic injury are not known in human neonates, evidence from adult humans $^{29}$ and neonatal piglets ${ }^{30}$ indicates that aerobic metabolism is impaired when cerebral $\mathrm{rSO}_{2}$ decreases below $44 \%$ to $47 \%$. Critically low values for cerebral $\mathrm{rSO}_{2}$ have been reported preoperatively in neonates with a variety of congenital lesions ${ }^{31}$ and were observed with substantial frequency in our patients in the post-CPB period.

The pre-CPB $\mathrm{rSO}_{2}$ data revealed a normal cerebral arterial-regional saturation difference ${ }^{31}$ but an increased somatic arterial-regional difference, typical of a "stressed" patient with increased resistance in vascular beds subject to regional sympathetic control, with resultant redistribution of systemic perfusion from splanchnic to cerebral circulations. The baseline hemodynamic data in these infants revealed high $\mathrm{SaO}_{2}$ and high pulmonary and systemic flow ratios despite preoperative management with hypercapnia and low $\mathrm{FIO}_{2}$; thus, compromised splanchnic and somatic flow were expected.

Before $\mathrm{CPB}, \mathrm{SvO}_{2}$ was slightly lower than cerebral $\mathrm{rSO}_{2}$, reflecting the contribution of relatively desaturated somatic blood to $\mathrm{SvO}_{2}$. After CPB, the converse was true; $\mathrm{SvO}_{2}$ was higher than cerebral $\mathrm{rSO}_{2}$, reflecting the contribution of more well-saturated somatic blood to $\mathrm{SvO}_{2}$. These findings emphasize the differences between regional and global measures of oxygen supply and demand relationships. ${ }^{18,32}$

The observed divergence of cerebral from somatic $\mathrm{rSO}_{2}$ post-CPB was expected, ${ }^{33}$ although the decrease in cerebral $\mathrm{rSO}_{2}$ from the pre-CPB baseline indicates that cerebral oxygenation may be vulnerable despite palliation of the circulation through S1P. The reasons for the reduction in cerebral $\mathrm{rSO}_{2}$ from baseline include (1) reduced global oxygen delivery, (2) reduced somatic and splanchnic resistance, (3) increased cerebral resistance, and (4) changes in the venous blood compartment.

Although global oxygen delivery $\left(\mathrm{SvO}_{2}\right)$ was not routinely assessed preoperatively, $\mathrm{SvO}_{2}$ was maintained after separation from CPB until closure. Similarly, the $\mathrm{CaO}_{2}$. PPI, a measure of regional oxygen availability, was maintained post-CPB. Thus the decrease in cerebral $\mathrm{rSO}_{2}$ post$\mathrm{CPB}$ was not likely explained by a reduction in global oxygen delivery. However, because previous data have described the occurrence of decreasing $\mathrm{SvO}_{2}$ in the first 6 to 12 hours postoperatively, ${ }^{34}$ a reduction in global oxygen delivery may increase the risk of cerebral desaturation in the later postoperative period.

A reduction in splanchnic and somatic resistance by reactive hyperemia, phenoxybenzamine, milrinone, and 

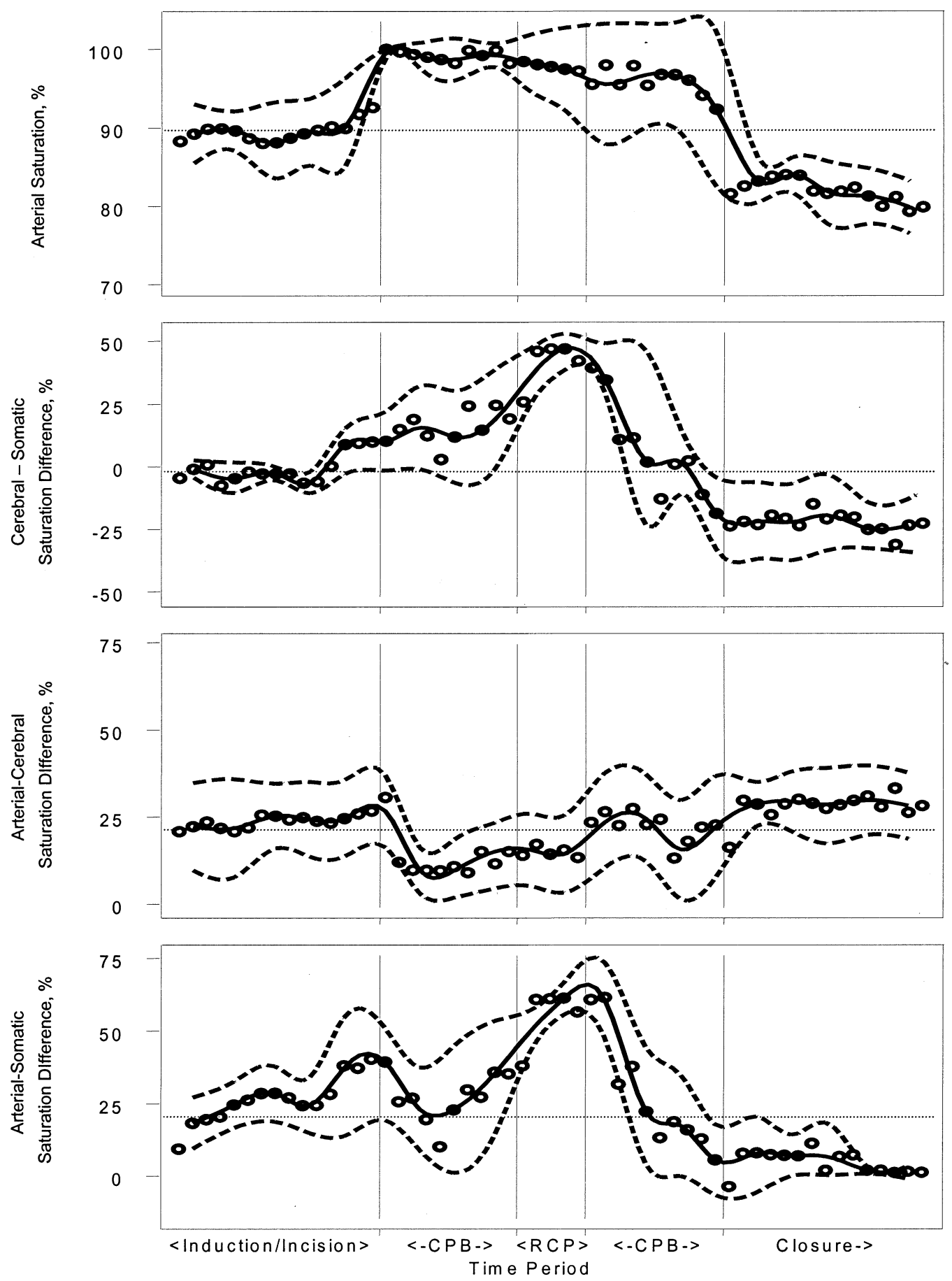

Figure 2. $\mathrm{SaO}_{2}$, cerebral-somatic $\mathrm{DrSO}_{2}$, cerebral Da-rO as mean and SD for each epoch. Dotted lines mark baseline measures for each parameter. CPB, Cardiopulmonary bypass; $R C P$, regional cerebral perfusion.

isoflurane likely contributed to the low risk of somatic desaturation in the immediate post-CPB period. Alpha-adrenergic mechanisms of vasoconstriction are more active in splanchnic, muscle, and skin beds than in organs with intense autoregulation such as brain and heart. ${ }^{35-37}$ Therefore, alpha-adrenergic blockade would be expected to reduce the sympathetically mediated increase in somatic resistance that occurs in the patient post-CPB with reduced 
TABLE 3. Complete hemodynamic data

\begin{tabular}{|c|c|c|c|c|c|}
\hline Parameter & Baseline & Induction & Incision & CPB & AoX \\
\hline Duration (min) & $19 \pm 7$ & $21 \pm 6$ & $74 \pm 12$ & $42 \pm 9$ & $4 \pm 2$ \\
\hline $\mathrm{rSO}_{2}$ cerebral $(\%)$ & $68 \pm 4$ & $64 \pm 10$ & $65 \pm 9$ & $88 \pm 8$ & $87 \pm 8$ \\
\hline $\mathrm{rSO}_{2}$ somatic $(\%)$ & $68 \pm 8$ & $62 \pm 6$ & $56 \pm 14$ & $78 \pm 13$ & $69 \pm 19$ \\
\hline $\mathrm{SaO}_{2}(\%)$ & $90 \pm 3$ & $90 \pm 4$ & $91 \pm 5$ & $99 \pm 2$ & $99 \pm 2$ \\
\hline $\mathrm{SvO}_{2}(\%)$ & $@$ & @ & $63 \pm 14 @$ & $93 \pm 7$ & $92 \pm 4$ \\
\hline Temperature (centigrade) & $37.2 \pm 0.2$ & $37.1 \pm 0.3$ & $35.3 \pm 1.6$ & $21.5 \pm 4.2$ & $18.9 \pm 1.4$ \\
\hline Hematocrit $(\%)$ & $41 \pm 5$ & $41 \pm 6$ & $41 \pm 5$ & $25 \pm 2$ & $26 \pm 3$ \\
\hline $\operatorname{MABP}(\mathrm{mm} \mathrm{Hg})$ & $48 \pm 4$ & $46 \pm 6$ & $42 \pm 7$ & $32 \pm 9$ & $18 \pm 5$ \\
\hline CVP $(\mathrm{mm} \mathrm{Hg})$ & $9 \pm 4$ & $9 \pm 4$ & $9 \pm 4$ & $3 \pm 3$ & $4 \pm 2$ \\
\hline $\mathrm{PP}(\mathrm{mm} \mathrm{Hg})$ & $40 \pm 5$ & $38 \pm 5$ & $34 \pm 5$ & $30 \pm 8$ & $15 \pm 4$ \\
\hline $\mathrm{FlO}_{2}$ & $0.22 \pm 0.01$ & $0.22 \pm 0.01$ & $0.24 \pm 0.05$ & $0.43 \pm 0.06$ & $0.47 \pm 0.08$ \\
\hline $\mathrm{PaCO}_{2}$ (torr) & $44 \pm 7$ & $51 \pm 8$ & $50 \pm 10$ & $43 \pm 11$ & $47 \pm 13$ \\
\hline $\mathrm{PetcO}_{2}$ (torr) & $45 \pm 5$ & $46 \pm 8$ & $47 \pm 12$ & & \\
\hline Isoflurane (\%) & $0.23 \pm 0.09$ & $0.25 \pm 0.09$ & $0.27 \pm 0.13$ & $0.49 \pm 0.07$ & $0.47 \pm 0.08$ \\
\hline CPB flow $\left(\mathrm{mL} \cdot \mathrm{kg}^{-1} \cdot \mathrm{min}^{-1}\right)$ & & & & $195 \pm 62$ & $103 \pm 47$ \\
\hline CPB flow $\left(\mathrm{L} \cdot \mathrm{m}^{-2} \cdot \mathrm{min}^{-1}\right)$ & & & & $3.11 \pm 0.99$ & $1.65 \pm 0.70$ \\
\hline Da-rO ${ }_{2}$ cerebral $(\%)$ & $21 \pm 9$ & $26 \pm 11$ & $26 \pm 10$ & $11 \pm 9$ & $12 \pm 8$ \\
\hline Da-rO ${ }_{2}$ somatic $(\%)$ & $22 \pm 6$ & $30 \pm 9$ & $36 \pm 17$ & $22 \pm 13$ & $31 \pm 20$ \\
\hline $\mathrm{DrSO}_{2}$ cerebral-somatic & $-1 \pm 6$ & $-3 \pm 5$ & $6 \pm 10$ & $12 \pm 13$ & $20 \pm 19$ \\
\hline $\mathrm{CaO}_{2} \cdot \mathrm{PP}$ index & $658 \pm 106$ & $628 \pm 145$ & $573 \pm 115$ & $322 \pm 94$ & $168 \pm 46$ \\
\hline
\end{tabular}

Detailed hemodynamic data at each of the 11 identified intervals presented as mean \pm SD. Cells with incomplete data are signified by @. $M A B P$, Mean arterial blood pressure; CVP, central venous pressure; $P P$, perfusion pressure; $A o X$, aortic crossclamp; MUF, modified ultrafiltration.

TABLE 4. Effect of CPB on determinants of cerebral $\mathrm{rSO}_{2}$

\begin{tabular}{|c|c|c|c|c|c|}
\hline Parameter & $\begin{array}{c}\text { Pre-CPB } \\
\text { coefficient }\end{array}$ & $P$ value & $\begin{array}{l}\text { Post-CPB } \\
\text { coefficient }\end{array}$ & $P$ value & $\begin{array}{l}P \text { value for } \\
\text { difference }\end{array}$ \\
\hline MABP $(\mathrm{mm} \mathrm{Hg})$ & $0.14 \pm 0.05$ & .002 & $0.43 \pm 0.07$ & $<.001$ & $<.001$ \\
\hline $\mathrm{SaO}_{2}(\%)$ & $0.19 \pm 0.05$ & $<.001$ & $0.19 \pm 0.05$ & $<.001$ & - \\
\hline CVP $(\mathrm{mm} \mathrm{Hg})$ & $-0.14 \pm 0.06$ & .026 & $-0.14 \pm 0.06$ & .026 & - \\
\hline Hematocrit $(\%)$ & $-1.39 \pm 0.03$ & $<.001$ & $1.14 \pm 0.07$ & $<.001$ & $<.001$ \\
\hline $\mathrm{PaCO}_{2}$ (torr) & $0.38 \pm 0.03$ & $<.001$ & $0.80 \pm 0.05$ & $<.001$ & $<.001$ \\
\hline Temperature (centigrade) & $-0.7 \pm 0.11$ & $<.001$ & $-4.65 \pm 0.32$ & $<.001$ & $<.001$ \\
\hline Isoflurane (\%) & $-21.5 \pm 1.33$ & $<.001$ & $26.1 \pm 1.5$ & $<.001$ & $<.001$ \\
\hline Constant & $106.5 \pm 8.3$ & $<.001$ & $106.5 \pm 8.3$ & $<.001$ & - \\
\hline
\end{tabular}

Table shows the coefficients for parameters that were significantly related to cerebral $\mathrm{rSO}_{2}$ in a $\mathrm{GLS}$ regression model using all pre- and post-CPB data points $(\mathrm{N}=2390)$. Parameter coefficient shows change in $\mathrm{rSO}_{2}$ for unit change in parameter. Model $\mathrm{R}^{2}$ was 0.75 within patient, 0.89 between patients, and 0.79 overall. $P$ value for difference compares pre-CPB with post-CPB coefficient. The effects of MABP, hematocrit, Paco ${ }_{2}$, temperature, and isoflurane concentration were significantly altered by CPB.

$G L S$, Generalized least square.

oxygen delivery. Our findings provide direct evidence for an effect of phenoxybenzamine to preserve perfusion in somatic beds. However, the cerebral circulation may be more vulnerable if splanchnic vasoconstriction is pharmacologically limited. Further study is necessary to quantify the potential effect of phenoxybenzamine to redistribute blood flow away from the cerebral circulation.

The decreased cerebral $\mathrm{rSO}_{2}$ corresponded in time to a decrease in isoflurane concentration; isoflurane decreases both cerebral oxygen consumption and cerebrovascular resistance, with a resultant increase in cerebral oxygenation. ${ }^{38}$
Although isoflurane similarly alters autoregulation in all systemic beds by its vasodilatory effects, additional somatic vasodilation may not have occurred in the presence of phenoxybenzamine and milrinone. Thus, the effect of isoflurane to increase cerebral blood flow may be enhanced in the presence of additional pharmacologic reduction in somatic resistance.

Cerebral resistance is increased after hypothermic circulatory arrest and hypothermic CPB..$^{1,5,15}$ This may occur as result of altered dynamic autoregulation from changes in $\mathrm{PCO}_{2}$ and $\mathrm{pH}$ as a result of impaired autoregulation, ${ }^{15,16}$ 


\begin{tabular}{|c|c|c|c|c|c|c|}
\hline RCP & CPB & AoX off & Off CPB & $\begin{array}{c}\text { MUF } \\
\text { performed }\end{array}$ & Closure & $\begin{array}{c}\text { Overall } \\
\text { total }\end{array}$ \\
\hline $58 \pm 10$ & $7 \pm 5$ & $59 \pm 9$ & $19 \pm 5$ & $61 \pm 12$ & $11 \pm 8$ & $353 \pm 39$ \\
\hline $81 \pm 9$ & $76 \pm 15$ & $77 \pm 10$ & $56 \pm 7$ & $52 \pm 9$ & $48 \pm 7$ & $70 \pm 15$ \\
\hline $41 \pm 7$ & $56 \pm 17$ & $86 \pm 8$ & $79 \pm 8$ & $76 \pm 7$ & $78 \pm 4$ & $67 \pm 18$ \\
\hline $98 \pm 4$ & $97 \pm 5$ & $95 \pm 8$ & $83 \pm 3$ & $82 \pm 4$ & $81 \pm 3$ & $92 \pm 8$ \\
\hline $89 \pm 8$ & $76 \pm 17$ & $79 \pm 13$ & $63 \pm 6$ & $61 \pm 6$ & $62 \pm 4$ & $77 \pm 16$ \\
\hline $19.6 \pm 2.9$ & $20.5 \pm 3.2$ & $32.1 \pm 5.1$ & $35.2 \pm 2.2$ & $36.1 \pm 0.7$ & $36.5 \pm 0.5$ & $30 \pm 8$ \\
\hline $27 \pm 3$ & $31 \pm 6$ & $32 \pm 4$ & $38 \pm 4$ & $42 \pm 3$ & $45 \pm 3$ & $35 \pm 8$ \\
\hline $17 \pm 8$ & $27 \pm 9$ & $44 \pm 8$ & $49 \pm 4$ & $53 \pm 3$ & $52 \pm 3$ & $39 \pm 14$ \\
\hline $4 \pm 2$ & $3 \pm 2$ & $6 \pm 4$ & $10 \pm 3$ & $11 \pm 2$ & $10 \pm 2$ & $7 \pm 4$ \\
\hline $13 \pm 8$ & $24 \pm 9$ & $38 \pm 9$ & $38 \pm 6$ & $42 \pm 4$ & $42 \pm 4$ & $32 \pm 12$ \\
\hline $0.51 \pm 0.14$ & $0.53 \pm 0.17$ & $0.64 \pm 0.22$ & $0.62 \pm 0.20$ & $0.51 \pm 0.10$ & $0.51 \pm 0.14$ & $0.45 \pm 0.20$ \\
\hline \multirow[t]{2}{*}{$41 \pm 8$} & $41 \pm 6$ & $39 \pm 4$ & $40 \pm 3$ & $42 \pm 5$ & $46 \pm 6$ & $44 \pm 9$ \\
\hline & & $15 \pm 14$ & $29 \pm 5$ & $32 \pm 6$ & $35 \pm 5$ & $27 \pm 19$ \\
\hline $0.51 \pm 0.06$ & $0.49 \pm 0.09$ & $0.52 \pm 0.08$ & $0.34 \pm 0.21$ & $0.28 \pm 0.21$ & $0.04 \pm 0.07$ & $0.38 \pm 0.17$ \\
\hline $46 \pm 22$ & $111 \pm 68$ & $214 \pm 49$ & & & & $70 \pm 9$ \\
\hline $0.74 \pm 0.35$ & $1.75 \pm 1.06$ & $3.41 \pm 0.77$ & & & & $1.1 \pm 1.5$ \\
\hline $17 \pm 11$ & $21 \pm 13$ & $17 \pm 13$ & $28 \pm 8$ & $30 \pm 9$ & $33 \pm 8$ & $22 \pm 12$ \\
\hline $59 \pm 7$ & $44 \pm 17$ & $10 \pm 10$ & $6 \pm 9$ & $6 \pm 9$ & $2 \pm 2$ & $25 \pm 22$ \\
\hline $42 \pm 10$ & $27 \pm 22$ & $-8 \pm 14$ & $-24 \pm 13$ & $-21 \pm 13$ & $-27 \pm 7$ & $3.1 \pm 24$ \\
\hline $153 \pm 100$ & $312 \pm 94$ & $529 \pm 210$ & $556 \pm 145$ & $652 \pm 110$ & $679 \pm 87$ & $474 \pm 224$ \\
\hline
\end{tabular}

endothelial dysfunction, 3,6,8,9 tissue edema, microvascular occlusion, cerebral edema, or other mechanical factors. Perfusion at excessive pressure has been implicated in the cerebrovascular lesion induced by hypothermic CPB. ${ }^{12,16,39}$ Although we targeted a cerebral $\mathrm{rSO}_{2}$ greater than $75 \%$ during RCP, we did not systematically reduce flow rates in patients with cerebral $\mathrm{rSO}_{2}$ greater than $90 \%$. Although the RCP flows in our patients were in the same range $(25-75 \mathrm{~mL}$ $\cdot \mathrm{kg} \cdot \mathrm{min})$ as reported by others, ${ }^{12-14,39,40}$ excessive flow during RCP may also contribute to the increased cerebrovascular resistance seen after hypothermic CPB. A target of cerebral $\mathrm{rSO}_{2}$ or jugular bulb saturation greater than $90 \%$ during CPB cooling, as in preparation for $\mathrm{DHCA},{ }^{5}$ thus may not be advisable if RCP will be used.

The use of a $\mathrm{pH}$-stat perfusion strategy, although enhancing recovery of cerebral energetics ${ }^{41}$ if post-CPB PP is controlled, may contribute to this overperfusion lesion through alteration of cerebral autoregulation. ${ }^{16,42}$ Our results indicate that hypercapnia during pre-CPB management and $\mathrm{pH}$-stat $\mathrm{CPB}$ management may reset cerebrovascular autoregulation for $\mathrm{CO}_{2}$ to a higher level. The enhanced sensitivity of $\mathrm{rSO}_{2}$ to changes in $\mathrm{PP}$ and $\mathrm{CO}_{2}$ post-CPB (Table 4) is consistent with altered autoregulation. ${ }^{16}$ The increased dependency of the cerebral circulation on PP constitutes a physiologic risk in the patient with parallel circulation, because increases in systemic blood pressure and SVR will reduce systemic blood flow. ${ }^{43}$ On the other hand, $\mathrm{CO}_{2}$ responsiveness was en- hanced post-CPB in our patients, indicating that more aggressive use of hypercapnia may improve cerebral $\mathrm{rSO}_{2}$ even in the face of adequate global oxygen delivery measures.

Our findings emphasize the direct effect of hypothermic $\mathrm{CPB}$ and RCP on cerebrovascular resistance ${ }^{11,16,41}$ despite efforts to optimize regional oxygen delivery, ${ }^{44}$ including adjuncts to minimize the endothelial dysfunction from CPB. $^{6,8,9}$ Modifications in perfusion strategy to limit changes in $\mathrm{rSO}_{2}$ may provide a means to avoid both supplydependent oxygen conditions ${ }^{40}$ and overperfusion during hypothermia. ${ }^{12}$ Use of more moderate hypothermia during CPB and RCP may be justifiable under regional $\mathrm{rSO}_{2}$ guidance to reduce the alterations in cerebral resistance that result from deep hypothermia. However, the relationship between the effects of DHCA and hypothermic RCP on cerebral blood flow and metabolism, and any subsequent neurologic injury, is still unclear.

The cerebral circulation remains at risk post-CPB despite continuous cerebral perfusion, and neurologic dysfunction may result from postoperative cerebral ischemia independently of CPB techniques. Our results indicate that extended monitoring of brain oxygenation in the immediate postoperative period, when reduced global oxygen delivery is likely to be superimposed on increased cerebrovascular resistance, may reveal further opportunities for hemodynamic interventions to reduce the risk of cerebral ischemia. 


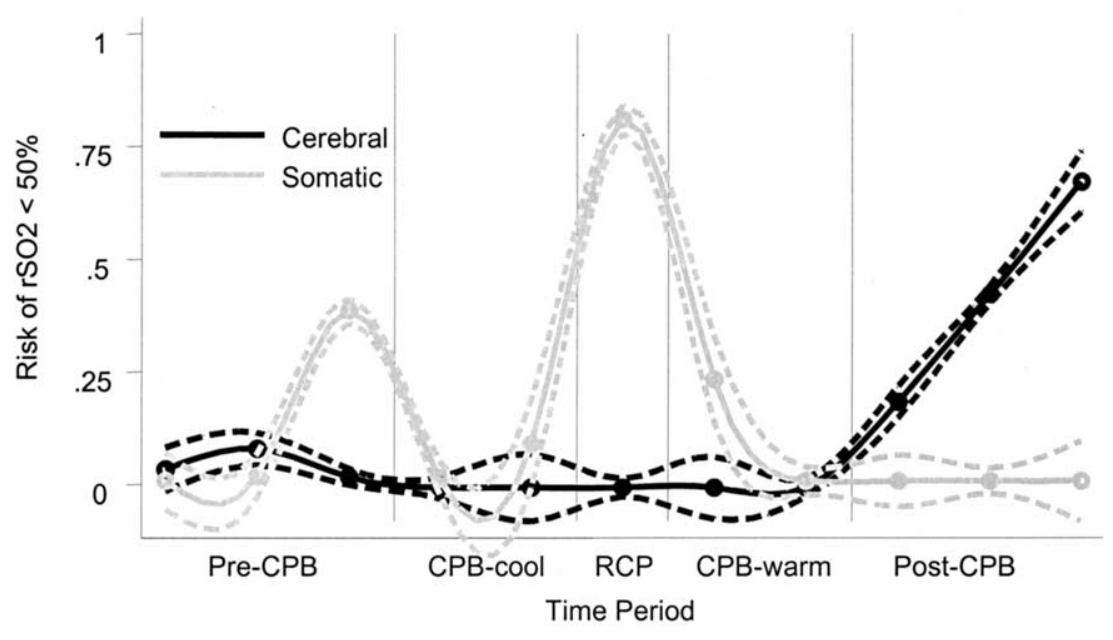

Figure 3. The risk of regional saturation less than $50 \%$ is shown as the absolute binomial risk (and $95 \% \mathrm{Cl}$ of this risk estimate) at each operative period. Significant somatic desaturation risk occurred after incision and during RCP. The risk of cerebral desaturation progressively increased post-CPB. CPB, Cardiopulmonary bypass; $R C P$, regional cerebral perfusion.

\section{References}

1. Duebener LF, Hagino I, Sakamoto T, Mime LB, Stamm C, Zurakowski D, et al. Effects of $\mathrm{pH}$ management during deep hypothermic bypass on cerebral microcirculation: alpha-stat versus $\mathrm{pH}$-stat. Circulation. 2002;106(12 Suppl 1):I103-8.

2. Jonas RA, Bellinger DC, Rappaport LA, Wernovsky G, Hickey PR, Farrell DM, et al. Relation of pH strategy and developmental outcome after hypothermic circulatory arrest. J Thorac Cardiovasc Surg. 1993; 106:362-8

3. Shin'oka T, Shum-Tim D, Jonas RA, Lidov HG, Laussen PC, Miura T, et al. Higher hematocrit improves cerebral outcome after deep hypothermic circulatory arrest. Thorac Cardiovasc Surg. 1996;112:161020 .

4. Kurth CD, Steven JM, Nicolson SC, Jacobs ML. Cerebral oxygenation during cardiopulmonary bypass in children. $J$ Thorac Cardiovasc Surg. 1997;113:71-8.

5. Mault JR, Whitaker EG, Lodge AJ, Greeley WJ, Ungerleider RM. Cerebral metabolic effects of sequential periods of hypothermic circulatory arrest. Ann Thorac Surg. 1994;57:96-100.

6. Wagerle LC, Russo P, Dahdah NS, Kapadia N, Davis DA. Endothelial dysfunction in cerebral microcirculation during hypothermic cardiopulmonary bypass in newborn lambs. Thorac Cardiovasc Surg. 1998; 115:1047-54.

7. Aoki M, Nomura F, Stromski ME, Tsuji MK, Fackler JC, Hickey PR, et al. Effects of $\mathrm{pH}$ on brain energetics after hypothermic circulatory arrest. Ann Thorac Surg. 1993;55:1093-103.

8. Aoki M, Jonas RA, Nomura F, Stromski ME, Tsuji MK, Hickey PR, et al. Effects of aprotinin on acute recovery of cerebral metabolism in piglets after hypothermic circulatory arrest. Ann Thorac Surg. 1994; 58:146-53.

9. Langley SM, Chai PJ, Jaggers JJ, Ungerleider RM. Preoperative high dose methylprednisolone attenuates the cerebral response to deep hypothermic circulatory arrest. Eur J Cardiothorac Surg. 2000;17: 279-86.

10. Olsen KS, Svendsen LB, Larsen FS. Validation of transcranial nearinfrared spectroscopy for evaluation of cerebral blood flow autoregulation. J Neurosurg Anesthesiol. 1996;8:280-5.

11. Kadoi Y, Kawahara F, Saito S, Morita T, Kunimoto F, Goto F, et al. Effects of hypothermic and normothermic cardiopulmonary bypass on brain oxygenation. Ann Thorac Surg. 1999;68:34-9.

12. Andropoulos DB, Stayer SA, McKenzie ED, Fraser CD Jr. Novel cerebral physiologic monitoring to guide low-flow cerebral perfusion during neonatal aortic arch reconstruction. J Thorac Cardiovasc Surg. 2003;125(3 Pt 1):491-9.

13. Pigula FA. Arch reconstruction without circulatory arrest: scientific basis for continued use and application to patients with arch anomalies. Semin Thorac Cardiovasc Surg Pediatr Card Surg Annu. 2002;5:10415 .

14. Pigula FA, Nemoto EM, Griffith BP, Siewers RD. Regional low-flow perfusion provides cerebral circulatory support during neonatal aortic arch reconstruction. J Thorac Cardiovasc Surg. 2000;119:331-9.

15. Greeley WJ, Ungerleider RM, Smith LR, Reves JG. The effects of deep hypothermic cardiopulmonary bypass and total circulatory arrest on cerebral blood flow in infants and children. $J$ Thorac Cardiovasc Surg. 1989;97:737-45.

16. Abdul-Khaliq H, Uhlig R, Bottcher W, Ewert P, Alexi-Meskishvili V, Lange PE. Factors influencing the change in cerebral hemodynamics in pediatric patients during and after corrective cardiac surgery of congenital heart diseases by means of full-flow cardiopulmonary bypass. Perfusion. 2002;17:179-85.

17. Tweddell JS, Hoffman GM. Postoperative management of patients with complex congenital heart disease. Semin Thorac Cardiovasc Surg Pediatr Card Surg Annu. 2002;5:187-205.

18. Rasanen J, Peltola K, Leijala M. Superior vena caval and mixed venous oxyhemoglobin saturations in children recovering from open heart surgery. J Clin Monit. 1992;8:44-9.

19. Hoffman GM, Ghanayem NS, Kampine JM, Berger S, Mussatto KA, Litwin SB, et al. Venous saturation and the anaerobic threshold in neonates after the Norwood procedure for hypoplastic left heart syndrome. Ann Thorac Surg. 2000;70:1515-20.

20. Pigula FA, Gandhi SK, Siewers RD, Davis PJ, Webber SA, Nemoto EM. Regional low-flow perfusion provides somatic circulatory support during neonatal aortic arch surgery. Ann Thorac Surg. 2001;72:401-6.

21. Tabbutt S, Ramamoorthy C, Montenegro LM, Durning SM, Kurth CD, Steven JM, et al. Impact of inspired gas mixtures on preoperative infants with hypoplastic left heart syndrome during controlled ventilation. Circulation. 2001;104(12 Suppl 1):I159-64.

22. Anand KJ, Hickey PR. Halothane-morphine compared with high-dose sufentanil for anesthesia and postoperative analgesia in neonatal cardiac surgery. $N$ Engl J Med. 1992;326:1-9.

23. Tweddell JS, Hoffman GM, Mussatto KA, Fedderly RT, Berger S, Jaquiss $\mathrm{RD}$, et al. Improved survival of patients undergoing palliation of hypoplastic left heart syndrome: lessons learned from 115 consecutive patients. Circulation. 2002;106(12 Suppl 1):I82-9. 
24. Grubhofer G, Tonninger W, Keznickl P, Skyllouriotis P, Ehrlich M, Hiesmayr M, et al. A comparison of the monitors INVOS 3100 and NIRO 500 in detecting changes in cerebral oxygenation. Acta Anaesthesiol Scand. 1999;43:470-5.

25. Muellner T, Nikolic A, Schramm W, Vecsei V. New instrument that uses near-infrared spectroscopy for the monitoring of human muscle oxygenation. J Trauma. 1999;46:1082-4.

26. Abdul-Khaliq H, Troitzsch D, Schubert S, Wehsack A, Bottcher W, Gutsch E, et al. Cerebral oxygen monitoring during neonatal cardiopulmonary bypass and deep hypothermic circulatory arrest. Thorac Cardiovasc Surg. 2002;50:77-81.

27. Austin EH 3rd, Edmonds HL Jr, Auden SM, Seremet V, Niznik G, Sehic A, et al. Benefit of neurophysiologic monitoring for pediatric cardiac surgery. J Thorac Cardiovasc Surg. 1997;114:707-15, 717.

28. Nollert G, Jonas RA, Reichart B. Optimizing cerebral oxygenation during cardiac surgery: a review of experimental and clinical investigations with near infrared spectrophotometry. Thorac Cardiovasc Surg. 2000;48:247-53.

29. Levy WJ, Levin S, Chance B. Near-infrared measurement of cerebral oxygenation. Correlation with electroencephalographic ischemia during ventricular fibrillation. Anesthesiology. 155;83:738-46.

30. Kurth CD, Levy WJ, McCann J. Near-infrared spectroscopy cerebral oxygen saturation thresholds for hypoxia-ischemia in piglets. J Cereb Blood Flow Metab. 2002;22:335-41.

31. Kurth CD, Steven JL, Montenegro LM, Watzman HM, Gaynor JW, Spray TL, et al. Cerebral oxygen saturation before congenital heart surgery. Ann Thorac Surg. 2001;72:187-92.

32. Yeh T Jr, Gouldman J, Auden SM, Seremet V, Edmonds HL Jr, Cerrito PB, et al. Mixed venous oxygen saturation does not adequately predict cerebral perfusion during pediatric cardiopulmonary bypass. J Thorac Cardiovasc Surg. 2001;122:192-3.

33. Daubeney PE, Smith DC, Pilkington SN, Lamb RK, Monro JL, Tsang VT, et al. Cerebral oxygenation during paediatric cardiac surgery: identification of vulnerable periods using near infrared spectroscopy. Eur J Cardiothorac Surg. 1998;13:370-7.

34. Tweddell JS, Hoffman GM, Fedderly RT, Ghanayem NS, Kampine JM, Berger S, et al. Patients at risk for low systemic oxygen delivery after the Norwood procedure. Ann Thorac Surg. 2000;69:1893-9.

35. Rogers AT, Progh DS, Roy RC, Gravlee GP, Stump DA, Cordell AR, et al. Cerebrovascular and cerebral metabolic effects of alterations in perfusion flow rate during hypothermic cardiopulmonary bypass in man. J Thorac Cardiovasc Surg. 1992;103:262-8.

36. O'Dwyer C, Woodson LC, Conroy BP, Lin CY, Deyo DJ, Uchida T, et al. Regional perfusion abnormalities with phenylephrine during normothermic bypass. Ann Thorac Surg. 1997;63:728-35.

37. Slater JM, Orszulak TA, Cook DJ. Distribution and hierarchy of regional blood flow during hypothermic cardiopulmonary bypass. Ann Thorac Surg. 2001;72:542-7.

38. Drummond JC, Todd MM, Scheller MS, Shapiro HM. A comparison of the direct cerebral vasodilating potencies of halothane and isoflurane in the New Zealand white rabbit. Anesthesiology. 1986;65:462-7.

39. DeCampli WM, Schears G, Myung R, Schultz S, Creed J, Pastuszko $\mathrm{A}$, et al. Tissue oxygen tension during regional low-flow perfusion in neonates. J Thorac Cardiovasc Surg. 2003;125(3 Pt 1):472-80.

40. Miyamoto K, Kawahimia Y, Matsuda H, Okuda A, Maeda S, Hirose H. Optimal perfusion flow rate for the brain during deep hypothermic cardiopulmonary bypass at 20 degrees C. An experimental study. J Thorac Cardiovasc Surg. 1986;92:1065-70.

41. Kurth CD, O'Rourke MM, O'Hara IB. Comparison of pH-stat and alpha-stat cardiopulmonary bypass on cerebral oxygenation and blood flow in relation to hypothermic circulatory arrest in piglets. Anesthesiology. 1998;89:110-8.

42. Murkin JM, Farrar JK, Tweed WA, McKenzie FN, Guiraudon G. Cerebral autoregulation and flow/metabolism coupling during cardiopulmonary bypass: the influence of PaCO2. Anesth Analg. 1987;66: 825-32.

43. Tweddell JS, Hoffman GM, Fedderly RT, Berger S, Thomas JP Jr, Ghanayem NS, et al. Phenoxybenzamine improves systemic oxygen delivery after the Norwood procedure. Ann Thorac Surg. 1999;67: 161-7.

44. Schears G, Shen J, Creed J, Zaitseva T, Wilson DF, Greeley WJ, et al.
Brain oxygenation during cardiopulmonary bypass and circulatory arrest. Adv Exp Med Biol. 2003;510:325-30.

\section{Discussion}

Dr Gil Wernovsky (Philadelphia, $\mathrm{Pa}$ ). I found this study to be quite innovative, well designed, and thoughtfully presented. It adds to the growing body of information on the complexities of single ventricle physiology, both before and after CPB.

In the past 15 years, there have been consistent and incremental improvements in the outcomes for children undergoing stage 1 reconstruction, and many things have changed because of our clinical experience and laboratory findings.

These include changes in the methods of preoperative stabilization, the timing of surgery (as you have described in regard to the institution of CPB, including a shift to RCP to avoid DHCA), and the medical management of these patients, with increasing use of postoperative, long-acting vasodilators (such as phenoxybenzamine) and frequent postoperative monitoring. Many of these advances have been pioneered by your group in Milwaukee and others in this room.

On the basis of these studies, there has been a shift at many centers to embrace these new practices. However, before this report, there has been little information presented on the potential neurologic morbidities of two of these changes- RCP and the routine use of phenoxybenzamine.

This article contains a substantial amount of data, but I want to comment on two points and then ask Dr Hoffman three questions.

On the basis of clinical laboratory data from a decade ago, many in our field have moved to avoid circulatory arrest whenever possible. However, a similar detailed assessment of this alternative, RCP in the human, is lacking.

The strategy of RCP for an average of approximately 1 hour in this study, which was preceded by bypass of approximately 45 minutes, and another period of 20 minutes or so after the period of RCP, was associated with estimates of adequate cerebral oxygen delivery by NIRS during the procedure, but significantly lower values after the procedure. As the authors state, this was not solely the result of a postoperative decrease in arterial oxygen saturation, but most likely the result of the increased postoperative cerebral vascular resistance caused by impaired autoregulation.

In addition, the patients received a potent systemic vasodilator (phenoxybenzamine) to minimize ventricular afterload.

Thus, following these combined strategies, a situation has been created that conspires to maximally shunt blood away from the central nervous system, high cerebrovascular resistance and low splanchnic resistance.

Now, this may or may not have clinical implications, and we just do not know yet. It is important to emphasize that NIRS is a surrogate variable for CNS oxygenation, and these observations must be followed up with clinical studies to determine the clinical relevance in the long term.

So I would like to ask the following three questions. First, the authors state that the rate of RCP was titrated during the procedure over a wide range (I believe it was $30-70 \mathrm{~mL} \cdot \mathrm{kg} \cdot \mathrm{min}$ ) to achieve a target cerebral saturation of $75 \%$ or greater during the procedure.

Did you look at whether the decrease in postoperative cerebral oxygenation was related at all to the absolute rate or pressure of the cerebral blood flow that you used? One could hypothesize that 
higher flow rates or pressure during profound hypothermia could cause more endothelial damage and impaired autoregulation.

Second, the model that related regional cerebral saturation to the hemodynamic and bypass parameters was elegant and very interesting. The authors found that RCP, treatment with phenoxybenzamine, and a number of potentially modifiable parameters were related to lower cerebral oxygen saturations, including mean arterial pressure, lower hematocrit, and, I think, higher temperature.

Earlier in the session, Dr Gaynor presented data showing in a more heterogenous group of children that low diastolic pressure in the coronary intensive care unit was related to an increased incidence of periventricular leukomalacia.

Have you looked at the cerebral oxygenation data in the postbypass period in terms of diastolic pressure in addition to mean arterial pressure, because this could be particularly low in patients with a diastolic runoff through the shunt?

Finally, if you brought this methodology into the intensive care unit, because, as your group has shown, the real vulnerable period is 6 to 12 hours later, would the cerebral somatic difference persist into the postoperative period?

You and your group are really to be commended for continuing to investigate the implications of the changes in our strategies and to provide us with real data rather than dogma as we move forward.

Dr Hoffman. I agree that spectroscopy measurements are surrogate outcome indicators. I anticipate that with collaboration from colleagues we will be able to answer your most important question: What does this have to do with the relationship between NIRS measures and subsequent neurologic outcome?

With regard to the potential conspiracy of afterload reduction and posthypothermic CPB-increased cerebrovascular resistance, I agree that this is a major caveat and find these data compelling indication for regional saturation monitoring in this population.

The controversial question that we didn't answer, because we have largely abandoned the use of total circulatory arrest, is whether the increase in cerebrovascular resistance after DHCA is greater or less than that observed with the continuous RCP techniques.

Your first question related to the effect of perfusion flow rates on changes in cerebrovascular resistance.

I could not do the analysis that you suggested. In actuality, the perfusion flow rates vary somewhat in response to surgical manipulations on a minute-to-minute basis; our data collection technique did not allow the degree of bypass flow tracking to enable the data analysis required to answer your question, so I would have to think about the methodology.

However, there are good data showing that overperfusion, either by pressure or flow, increases the cerebrovascular lesion seen after deep hypothermic CPB.

We typically, as I think other centers do, try to overflow with a $\mathrm{pH}$-stat cooling strategy to achieve a jugular venous saturation or regional NIRS saturation greater than $90 \%$ in anticipation of a potential period of cerebral circulatory arrest. I'm not sure that overperfusion is routinely necessary anymore if NIRS monitoring and continuous cerebral perfusion are used, and it may be that overperfusion is contributing to things.
You wondered about the effects of postoperative diastolic blood pressure and global hemodynamic vulnerability on cerebral perfusion. I certainly agree that the first 6 to 24 postoperative hours is the most vulnerable, critical period for these patients. We have some NIRS data for this time period, but it has not been analyzed.

Because of the anticipated postoperative vulnerability, we hope to use this technology in most postoperative patients. We're currently limited by the number of available devices, as most investigators are.

Dr Carlos Troconis (Caracas, Venezuela). Dr Hoffman, are we looking at the tip of an iceberg? Is the problem more profound? Should we look back into the cerebral fetal circulation in hypoplastic left heart syndrome? We will probably find many reports about the incidence of microcephaly with this syndrome and undeveloped microcirculation or high resistance in cerebral flow. Can you make comments on that?

Dr Hoffman. I don't know about confounding anomalies of cerebrovascular anatomy in these patients. We have to deal with what we get. We can't change who comes to us. Preoperative management is important and has obvious implications for regional perfusion, and for most people in the room, there is probably less control over that than the immediate perioperative management.

Certainly the Philadelphia group has detected profound cerebral desaturation in a diverse group of cardiac neonates preoperatively. We didn't see that here. We observed relatively normal arterial-to-brain saturation differences in these patients preoperatively, indicating adequate cerebrovascular development but the potential for wide ranges of cerebral flow related to differences in preoperative management. So the potential certainly exists.

We have the advantage of extensive monitoring during a very intense period of operative intervention, but, as you pointed out, the horse could leave the barn before we get to the operating room, or, as Dr Wernovsky anticipated, sometime afterward.

Dr Richard A. Jonas (Boston, Mass). I have a question about the positioning of your oximetrics catheter and wonder if it was truly in the jugular bulb. If it was in the superior vena cava, then you were looking at a mix of jugular venous blood and somatic venous blood. And I very much doubt your speculation that the decrease in saturation is not likely to be caused by reduced cerebral oxygen delivery.

You have proposed that there is an increase in cerebrovascular resistance, which presumably reduces cerebral blood flow and cerebral oxygen delivery.

In fact, what I would suggest is that it is very likely that cerebral blood flow, and therefore oxygen delivery, is decreased related to the position of the shunt. I believe you have created a steal from the cerebral circulation. I am going to be fascinated to see you repeat the study, which I'm sure you will, when you perform the right ventricle to pulmonary artery shunt. I believe this will show quite a different result relative to what you presented today.

I think cerebral blood flow might also be decreased because of increased cerebrovascular resistance related to edema, secondary to your use of regional perfusion.

And incidentally, if I could make a plea, RCP has been the abbreviation for retrograde cerebral perfusion, and we are really going to have to come up a different acronym for RCP, otherwise the literature is going to get very confusing. 
In conclusion, until we have some mechanism for monitoring the adequacy of cerebral flow or excessive flow, you run a real risk of causing cerebral edema with regional perfusion. So that might be an additional cause for reduced cerebral blood flow. But I'm interested in the catheter position you used.

Dr Hoffman. The superior vena cava catheters are placed approximately $1 \mathrm{~cm}$ above the superior vena cava-right atrial junction, and we attempted to thread this up to the jugular bulb in only 1 patient.

So yes, the superior vena cava saturation is not the same as cerebral NIRS saturation. We do have data relating those two, which will be presented subsequently.

I think your point about the innominate take-off and potential cerebral steal is true, and it will be interesting to compare this cerebral NIRS data with patients who derive pulmonary blood flow from a right ventricular shunt.

The point I was trying to make about oxygen delivery was that whole-body oxygen delivery was not decreased. Therefore I agree completely that this decreased cerebral saturation we observed post-CPB is likely caused by decreased cerebral oxygen delivery related to regional resistance changes.

Dr Ross M. Ungerleider (Portland, Ore). On this basis, have you changed your postoperative strategy at all?

I mean, it seems that the most simple and straightforward thing you could do would be to keep $\mathrm{PCO}_{2}$ higher as you come off bypass, and $\mathrm{PCO}_{2}$ is related to cerebral blood flow. And in the face of the runoffs you are talking about (that you can't really do very much about it), it would seem that it might modify this. Have you tried that?

Dr Hoffman. We have used this device in a number of patients, and the effect of $\mathrm{CO}_{2}$ is immediate and apparent to anybody who bothers to look.

So yes, we have used more hypercapnia, as others have suggested, with the advantage of regional oxygenation data to guide this strategy. 